\title{
RETRACTED CHAPTER: Requirements for Battery Enclosures - Design Considerations and Practical Examples
}

Jobst H. Kerspe and Michael Fischer

The publisher retracted this chapter, because as it was inclu. ed cue to an unfortunate administrative error. The editors and the publisher apo ize or any inconvenience caused. The authors have agreed to this retraction. 